\title{
Genotoxicity of tetrahydrofolic acid to hematopoietic stem and progenitor cells
}

\author{
Clara B. García-Calderón ${ }^{1}$ • José Antonio Bejarano-García ${ }^{1}$ Isabel Tinoco-Gago ${ }^{1}$ • María José Castro ${ }^{1}$. \\ Paula Moreno-Gordillo ${ }^{1}$ José I. Piruat ${ }^{1,2}$ - Teresa Caballero-Velázquez ${ }^{1,2} \cdot$ José A. Pérez-Simón $^{1,2}$. \\ Iván V. Rosado $\mathbb{i D}^{1,3}$
}

Received: 19 June 2017 / Revised: 19 January 2018 / Accepted: 8 February 2018 / Published online: 6 March 2018

(c) ADMC Associazione Differenziamento e Morte Cellulare 2018

\begin{abstract}
Metabolically reactive formaldehyde is a genotoxin and a carcinogen. Mice lacking the main formaldehyde-detoxifying gene Adh5 combined with the loss of the Fanconi anemia (FA) DNA repair pathway rapidly succumbed to bone marrow failure (BMF) primarily due to the extensive ablation of the hematopoietic stem cell (HSC) pool. However, the mechanism by which formaldehyde mediates these toxic effects is still unknown. We uncover a detrimental role of tetrahydrofolic acid (THF) in cells lacking Adh5 or the FA repair pathway. We show that Adh5- or FA-deficient cells are hypersensitive to formaldehyde and to THF, presenting DNA damage and genome instability. THF cytotoxicity involved imbalance of the nucleotide pool by deregulation of the thymidylate synthase (TYMS) enzyme, which stalled replication forks. In mice, THF exposure had widespread effects on hematopoiesis, affecting the frequency and the viability of myeloid- and lymphoidcommitted precursor cells. Moreover, the hematopoietic stem and progenitor cells (HSPC) showed genomic instability, reduced colony-forming capacity and increased frequency of cycling and apoptotic HSCs upon THF exposure. Overall, our data reveal that the physiological pool of THF and formaldehyde challenge the stability of the genome of HSPCs that might lead to blood disorders.
\end{abstract}

\section{Introduction}

Prevention of DNA mutations through control of the cell cycle checkpoints response and active repair ensure the stability of the genome [1]. Depending upon the nature of the damage, cells have evolved several DNA repair

\section{Edited by M. Oren}

Electronic supplementary material The online version of this article (https://doi.org/10.1038/s41418-018-0089-4) contains supplementary material, which is available to authorized users.

$\triangle$ Iván V. Rosado

ivrosado@us.es

1 Instituto de Biomedicina de Sevilla (IBiS)/CSIC/Universidad de Sevilla/Campus Hospital Universitario Vírgen del Rocío 41013 Seville, Spain

2 Departamento de Hematología, Hospital Universitario Virgen del Rocío 41013 Seville, Spain

3 Departamento de Genética, Universidad de Sevilla 41013 Seville, Spain mechanisms [2]. The Fanconi anemia (FA) DNA repair pathway is activated upon DNA damage caused by chemical agents such as reactive aldehydes [3-7]. The FA pathway repairs interstrand crosslinks (ICLs), DNA lesions that halt DNA replication and/or transcription [8]. The FA pathway promotes the incision steps at ICL sites by a mechanism that is not fully understood [9-15]. It has also been recently proposed that the FA proteins are required to stabilize stalled replication forks, therefore protecting them from nucleolytic degradation [16, 17].

Mutations in any of the FA genes cause bone marrow failure (BMF), developmental defects, and cancer predisposition [18]. FA is a rare genetic disorder mainly characterized by hematological defects including reduced numbers of all blood cells (pancytopenia), progressive BMF, and a strikingly high predisposition to myelodysplastic syndrome/acute myeloid leukemia (AML) [19, 20]. The unifying feature of these patients is the development of BMF early in life due to the loss of the hematopoietic stem cell (HSC) pool [21, 22]. However, to date, none of the single FA knockout mouse models generated developed BMF [23, 24]. Furthermore, it 
has recently been reported that accumulation of toxic reactive aldehydes, reactive oxygen species, or metabolites produced during the TGF-mediated inflammation process challenges HSC homeostasis, eventually leading to BMF [3, 4, 25-28]. Adh5 and Aldh2, the main formaldehyde, and acetaldehyde-cleansing enzymes, play a critical role in the avoidance of aldehyde-DNA adducts [3, 4]. Strikingly, chicken Fanconi DT40 cells rely on a functional $A d h 5$ gene to survive [6]. Moreover, FA mice lacking Adh5 or Aldh2 enzymes succumbed to BMF and lymphoblastic leukemia at the age of 3-12 months [3, 4]. These results taken together suggest that HSC from FA mice are likely protected from endogenously generated toxic aldehydes by these enzymes, providing genetic evidence of the genotoxic consequences of the accumulation of reactive aldehydes to HSC. However, the mechanism by which reactive aldehydes affect cell survival is still unknown.

The biologically active vitamin B9 folate derivative THF is a water-soluble vitamin involved in DNA maintenance by acting as a donor of one-carbon groups during key DNA transactions [29-31]. THF serves as an acceptor of free formaldehyde, producing 5,10-me-THF [32]. The negative consequences of low-dietary folate intake during development cause incomplete closure of the neural tube, thus increasing the risk of meningocoele and spina bifida [3335]. To lower the prevalence of neural tube defects, countries like Canada or USA mandated folate fortification, however, up to $40 \%$ of people under study showed very high folate blood concentrations [36]. Whereas extensive efforts have clarified the well-demonstrated beneficial role of folate supplementation in the prevention of neural tube defects, very few reports address the toxic consequences of folate overload [37].

In this paper, we describe the detrimental consequences of excess THF and formaldehyde as drivers of genome instability and HSC dysfunction. We show that THF exposure is cytotoxic to Adh5- and FA-deficient cells due to the accumulation of extensive DNA damage and chromosome breaks. THF exposure activated the DNA damage response (DDR) due to uncontrolled activity of the TYMS enzyme, which caused a depletion of essential nucleotides, and promoted repair by a homologous recombination mechanism. In vivo and ex vivo exposure of hematopoietic cells to THF perturbed hematopoiesis, increased ser139-H2AX phosphorylation, and decreased the survival of HSPCs suggesting that excess THF could be mutagenic and genotoxic to bone marrow cells. This work uncovers an unsuspected relationship between THF and formaldehyde affecting the function and maintenance of HSPCs, which could ultimately lead to BMF and leukemia onset.

\section{Methods}

\section{Cell lines and reagents}

Chicken DT40 cell lines kindly provided by Dr. K.J. Patel were published elsewhere $[6,7,38,39]$. DT40 cells were cultured in RPMI1640 media supplemented with $7 \%$ fetal bovine serum, $3 \%$ chicken serum, $50 \mu \mathrm{M} 2$-mercaptoethanol, penicillin/streptomycin in a $10 \% \mathrm{CO}_{2}$ incubator at $37^{\circ}$ C. Cells were split daily. Tetrahydrofolic acid, folinic acid, folic acid, and S-adenosyl methionine were obtained (Sigma-Aldrich, Ltd.) and dissolved in PBS. KU55933, NU7026, and UCN-01 inhibitors (SantaCruz Biotechnology, Ltd.) were dissolved in DMSO $(10 \mathrm{mM}, 10 \mathrm{mM}$, and $250 \mu \mathrm{M}$, respectively) and added to a final concentration of $5 \mu \mathrm{M}, 20 \mu \mathrm{M}$, and $125 \mathrm{nM}$ to cultures $1 \mathrm{~h}$ before collecting. IMP, dUMP, and dCMP (Sigma-Aldrich, Ltd.) were dissolved in PBS (200 mM stock concentration) and added to cell cultures to a final concentration of $1 \mathrm{mM}$ for 3 days before THF exposure.

\section{Mouse experiments}

Adh5 $5^{-/-}$, FancD2 $2^{-/-}$, and congenic wild-type C57BL/6 were kindly provided by Dr. K.J. Patel lab with permission from Dr. Liu (UCSF) and Dr. Grompe (OHSU). Mice were maintained in a conventional mouse facility at the IBiS. Mice were intraperitoneally injected with THF at $62.5 \mathrm{mg}$ THF per kg per day. For BrdU staining of HSCs, BrdU was given in the drinking water for 7 days at $0.5 \mathrm{mg}$ per mouse per day. All animal experiments undertaken in this study were performed with the approval of the Hospital Universitario Vírgen del Rocío Ethical Review Committee.

\section{Protein extractions and immunoblots}

DT40 cell cultures were collected by centrifugation, washed in $1 \mathrm{~mL}$ of ice-cold PBS and lysed by pipetting up and down 20 times in $150 \mu$ l of ice-cold RIPA lysis buffer (RIPA buffer containing proteases, phosphatases, and deubiquitylases inhibitors (Roche)). Homogenates were incubated on ice for $30 \mathrm{~min}$ followed by centrifugation at 16,000 r.p.m. for $15 \mathrm{~min}$ at $4{ }^{\circ} \mathrm{C}$. Finally, supernatants (protein extracts) were quantitated by the Bradford method using a spectrophotometer. Samples were resolved on a PAGE gel, blotted onto a PVDF membrane and probed with an anti-FANCD2 (ab175382, Abcam), anti-PCNA (clone PC10, Sigma-Aldrich), anti-actin, anti-tubulin, anti-ser139 H2AX (JWB301, Millipore), or anti-ser345 CHK1 antibodies (Cell Signaling). Images were analyzed using the Fiji software. 


\section{Cytotoxicity assays}

A total of $5 \times 10^{3}$ DT40 cells were seeded into a 96-well plate and MTT assay was performed according to the manufacturer's instructions. Briefly, after 3 days of incubation at $37^{\circ} \mathrm{C}$, the assay was developed by adding Cell Proliferation Kit I (Roche) and quantitated using a plate reader at $550 \mathrm{~nm}$. For erythroid (CFU-E), granulocytemacrophage (CFU-GM), and pre-B (CFU-preB) colonyforming units, $2.5 \times 10^{5}, 2.5 \times 10^{4}$, and $5 \times 10^{5}$, respectively, of total bone marrow cells were exposed to various concentrations of THF in vitro for $4 \mathrm{~h}$ at $37^{\circ} \mathrm{C}$ in sealed cryovials. After treatment, two 10-fold serial dilutions of each vial were made, and seeded into 24-well plates containing MethoCult M3334, MethoCult M3534, and MethoCult M3630 (Stemcell Technologies, Ltd.), respectively. After incubation at $37^{\circ} \mathrm{C}$, colonies were counted after 3, 7, and 9 days, respectively, and represented as percentage of the untreated control condition. Each data point represents the mean of three mice per genotype in two independent experiments, each one carried out in duplicate.

\section{Chromosome aberrations and sister chromatid exchange assays}

To assess for chromosome aberrations, DT40 cells were grown on media containing the $25 \mu \mathrm{M}$ THF during $24 \mathrm{~h}$. One hour before collecting the cells, KaryoMAX colcemid solution (Gibco) was added at a final concentration of $0.1 \mu \mathrm{g} / \mathrm{ml}$. Cells were collected and incubated in a hypotonic solution $(75 \mathrm{mM} \mathrm{KCl})$ for $15 \mathrm{~min}$ at $37^{\circ} \mathrm{C}$. Fixative solution (3:1 methanol:acetic acid) was added, and cells were washed three times with this fixative solution. After washing, cells were resuspended in $500 \mu \mathrm{L}$ of fixative solution and spread on cleaned slides dropwise. The slides were stained with Giemsa 1:20 (Sigma-Aldrich) according to manufacturer instructions. To score chromosome aberrations, pictures of metaphases were scored with a DP72 camera attached to an Olympus BX61 optical microscope using $\times 100$ magnification lens and analyzed using Cellsense Dimension software. The pictures were scored blinded for chromosome aberrations. Sister chromatid recombination assay was performed as described in ref. [40] and analyzed using the microscope and software described for chromosome breaks test.

\section{Blood micronucleus test}

Blood micronucleus in peripheral blood upon THF exposure was quantified as previously described in ref. [40].

\section{Tetrahydrofolate and methanol exposure experiments}

A mixture of methanol, apple juice, and water (5:10:85) was given to 6-week-old mice as a source of fluid. Control group received apple juice and water. Weights were monitored daily. Soft food was added to all the cages until the weight recovered if $>10 \%$ weight loss was observed. When the exposure was ended, mice were culled and bone marrow isolated for analysis by flow cytometry to determine the frequency of HSCs, progenitor, and lineage-committed precursor cells.

\section{Colony-forming unit spleen $\left(\mathrm{CFU}-\mathrm{S}_{10}\right)$ assay}

Bone marrow cells were treated with THF for $4 \mathrm{~h}$ in sealed cryovials and injected intravenously into 8-12-weekold recipient mice that had been irradiated with $1000 \mathrm{cGy}$ split in two equal doses $3 \mathrm{~h}$ apart. A total of $1 \times 10^{5}$ nucleated bone marrow cells were used for wild-type, $A d h 5$ ${ }^{-/-}$, or FancD2 $2^{-/-}$bone marrow. Ten days after transplantation, the mice were killed, the spleens were fixed in Bouin solution overnight, and the colonies were enumerated.

\section{Competitive repopulation experiment}

A total of $2 \times 10^{5} \mathrm{Adh5^{-/- }}$ or appropriate control bone marrow cells (CD45.2) were treated with $200 \mu \mathrm{M}$ THF for $4 \mathrm{~h}$. Upon incubation, the cells were mixed with $2 \times 10^{5}$ competitor cells (CD45.1, B6.SJL-Ptprc ${ }^{a}$ Pepc $^{b} /$ BoyCrl, Harlan) and injected into lethally irradiated (1000 cGy, split between two doses $3 \mathrm{~h}$ apart) C57BL/6 (CD45.2) recipients. At least three recipients were used per condition. After 4, 8, 12, and 16 weeks, these recipients were bled and the contribution of mutant bone marrow to peripheral blood production was assessed by flow cytometry using CD45.1/CD45.2 antibodies. The expression of the surface markers CD45.1 and CD45.2 was analyzed in these populations using the antibodies against CD45.1-BV421 (clone A20) and CD45.2-APC (clone 104) from BD Bioscience. The percentage of test TER119- (nonerythroid) cells in the recipient blood was calculated as described previously.

\section{Analysis of HSPC, thymus, and spleen by flow cytometry}

Bone marrow cells were isolated from the femora and tibiae of mice by flushing cells and passing them through a 50- $\mu \mathrm{m}$ filter. Thymuses and spleen were mashed using a $5-\mathrm{mL}$ syringe plunge and passing them through a $50-\mu \mathrm{m}$ filter. Nucleated cells were enumerated using a solution of $3 \%$ acetic acid and methylene blue (Stemcell Technologies, 
Fig. 1 Folates cytotoxicity assay on DNA repair- and Adh5deficient DT40 cell lines. a Formaldehyde MTT assay on

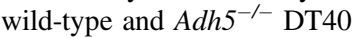
cells. b MTT assay of wild-type and $A d h 5^{-/-}$DT40 cells exposed to THF. c MTT assay of wild-type and $\mathrm{FancC}^{-}$and FancF $^{-1-}$ DT40 cells exposed to THF. d-f MTT assay of wildtype and $A d h 5^{-1-}$ DT40 cells exposed to folic acid, folinic acid, and adenosyl methionine, respectively. Data represent mean \pm s.d. of three independent experiments carried out in duplicates
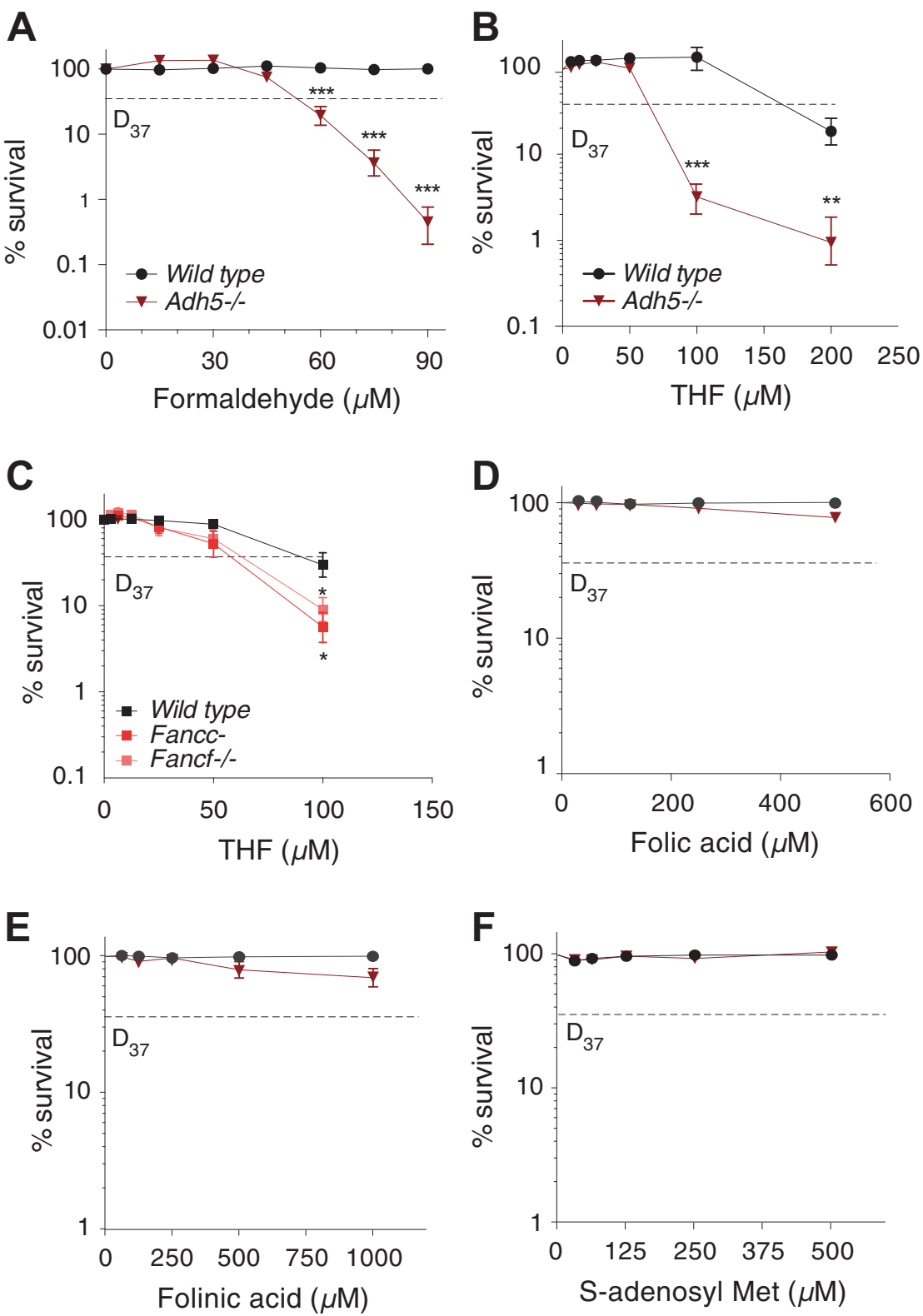

Ltd.) on a TC20 Cell counter (Bio-Rad). The following antibodies were used to stain for HSCs: Fluorescein isothiocyanate (FITC)-conjugated lineage cocktail with antibodies anti-CD3e (clone 145-2C11, Immunostep), anti-CD4 (clone H129.19, Immunostep), anti-CD8a (clone 53-6.7, Immunostep), anti-Ly-6G/Gr-1 (clone RB6-8C5, Immunostep), anti-CD11b/Mac-1 (clone M1/70, Immunostep), antiCD45R/B220 (clone RA3-6B2, Immunostep), Fce R1 $\alpha$ (clone MAR-1, eBioscience), anti-CD11c (clone N418, Immunostep) and anti-TER-119 (clone Ter119, Immunostep), anti-c-Kit (PerCP-Cy5.5, clone 2B8, eBioscience), and anti-Sca-1 (PE-Cy7, clone D7, eBioscience). After staining for $90 \mathrm{~min}$, the cells were washed. Bone marrow B cells were assessed using anti-CD45R/B220 (PE, clone
RA3-6B2, Immunostep). The erythroid lineage was analyzed using the anti-TER-119 antibody (APC, clone Ter119, Immunostep). Granulocyte and macrophages were assessed with antibodies anti-CD11b/Mac-1 (APC, clone M1/70, Immunostep) and anti-Ly-6G/Gr-1 (PE, clone RB6$8 \mathrm{C} 5$, eBioscience). Samples were run on a Fluorescenceactivated cell sorting (FACS) CantoII flow cytometer (BD Biosciences) and the data analyzed with FlowJo 10.1 (Tree Star).

\section{Cell sorting of LK and LKS BM cells}

Bone marrow cells were isolated from the femora and tibiae of mice by flushing cells and passing them through a $50-\mu \mathrm{m}$ 


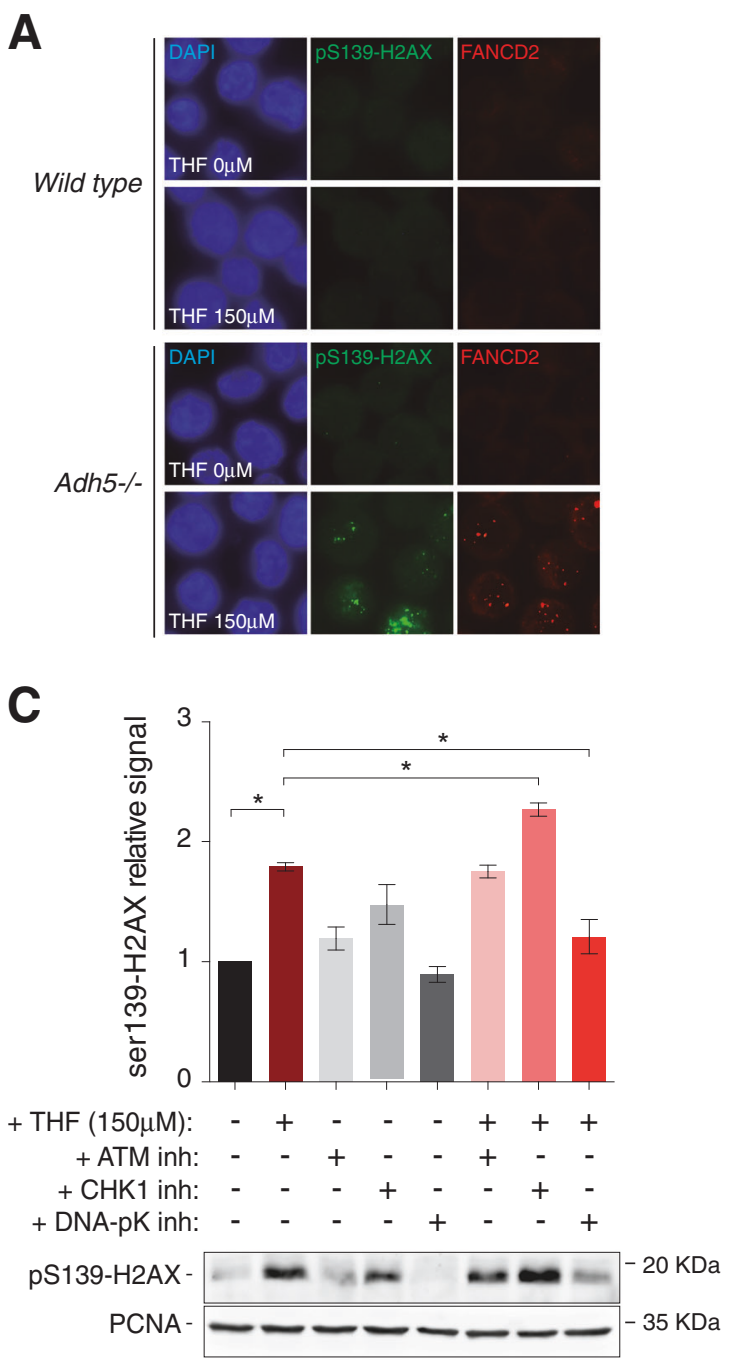

Fig. 2 THF causes DNA damage and genomic instability in Adh5deficient DT40 cells. a Immunofluorescence images of wild-type and $A d h 5^{-1-}$ cells exposed to THF for $4 \mathrm{~h}$, probed with anti-FANCD2 antibody and anti-ser139-H2AX. DAPI staining was included for pannuclear visualization of cells. b Western blot of wild-type, $A d h 5^{-/}$, and Fancf $^{-/}$DT40 whole-cell extracts upon exposure to increasing doses of THF for $16 \mathrm{~h}$. The membrane was probed with anti-FANCD2, anti-ser345-CHK1, anti-ser139-H2AX, and anti-PCNA antibodies. c Bottom, western blot of $A d h 5^{-/-}$whole-cell extracts upon exposure to THF $(150 \mu \mathrm{M})$ for $6 \mathrm{~h}$. ATM, CHK1, and DNA-pk inhibitors were added to the growth medium $1 \mathrm{~h}$ before collecting the cells. The

filter. Nucleated cells were enumerated, treated for $4 \mathrm{~h}$ with THF, and $90 \mathrm{~min}$ before THF treatment ends, the following antibodies were added to stain for HSCs: FITC, Fluorescein isothiocyanate-conjugated lineage cocktail, anti-c-Kit (PerCP-Cy5.5, clone 2B8, eBioscience), and anti-Sca-1 (PE-Cy7, clone D7, eBioscience). Upon incubation, the cells were washed in cold PBS and FACS-sorted using a BD FACSAria Fusion. Cells were spotted onto a glass slide, fixed, and permeabilized following manufacturer's instructions

E
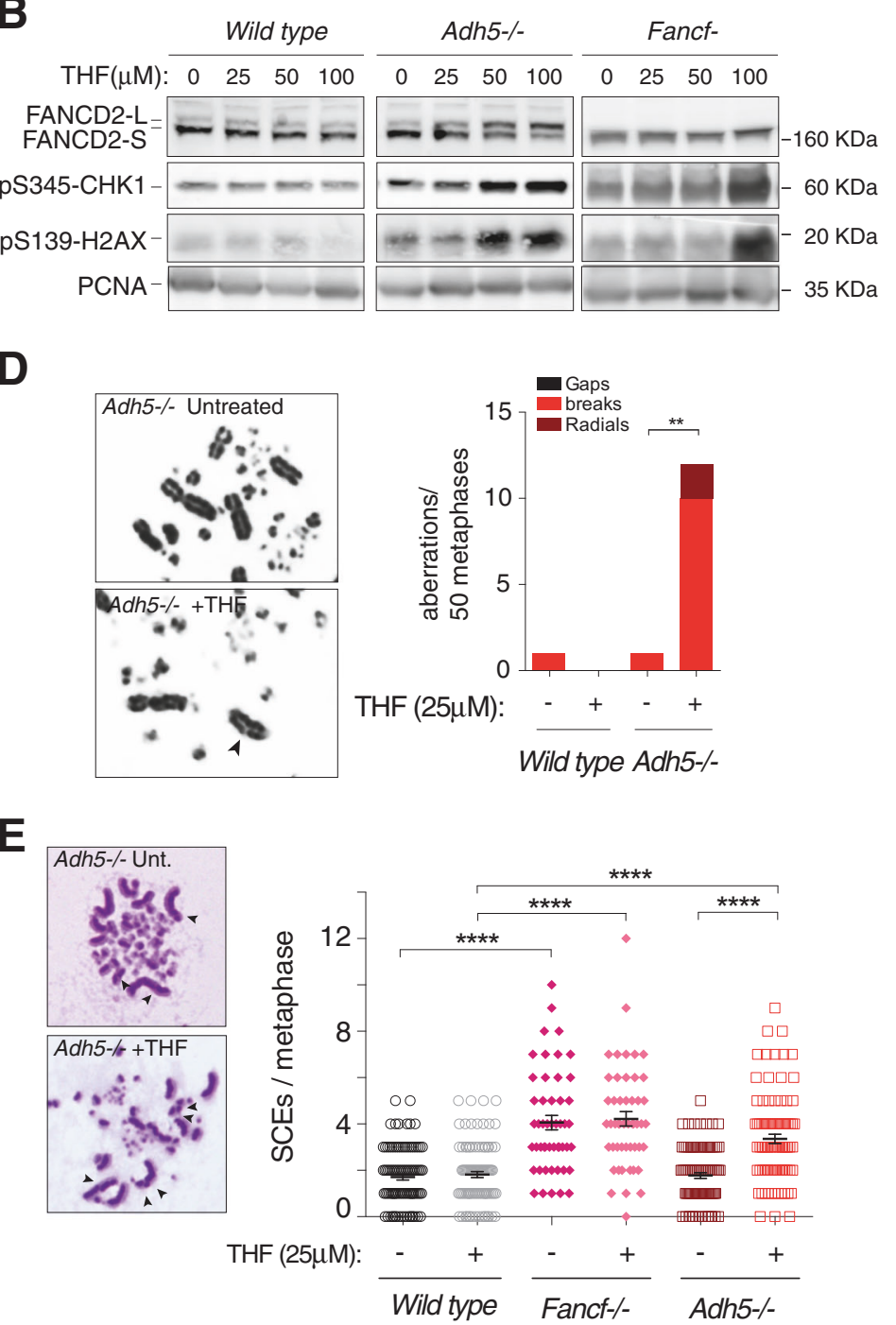

membrane was probed with anti-ser139-H2AX and anti-PCNA (loading control) antibodies. Representative images of two independent experiments are shown. Top, bar plot showing the quantitation of western blot using the Fiji software. d Left, representative images of $A d h 5^{-/-}$metaphase spreads upon THF exposure. Right, quantitation of breaks per metaphase in 100 metaphases per condition and genotype from two independent experiments. Student's $t$ test $P>0.05$. e Left, representative images of $A d h 5^{-1-}$ sister chromatid exchanges (SCEs) upon THF exposure. Right, quantitation of SCEs per metaphase in 50 metaphases per condition and genotype from two independent experiments. Student's $t$ test $P>0.05$

(Nordic MUbio, Ltd.), and stained with anti-ser139-H2AX antibody (JWB-301, Millipore, Merck) and DAPI.

\section{Statistical analysis}

Unless otherwise stated, the data reflect the mean \pm s.e.m. A two-tailed Student's $t$ test was used to assess the statistical significance $(* P<0.05, \quad * * P<0.01$, $* * * P<0.001, * * * * P<0.0001)$. 
A

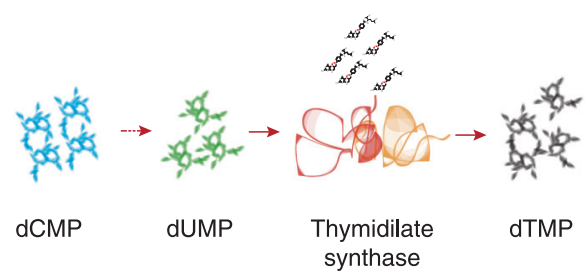

B

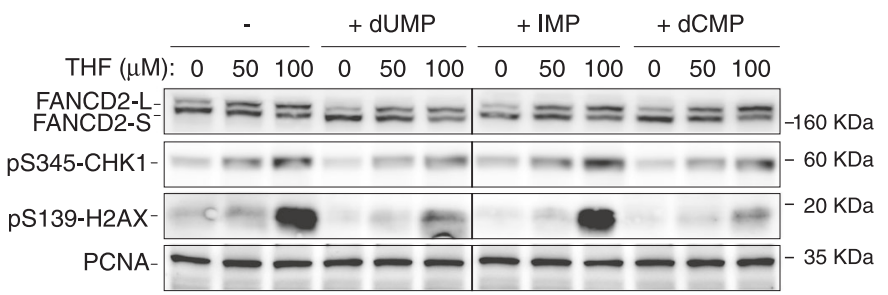

C

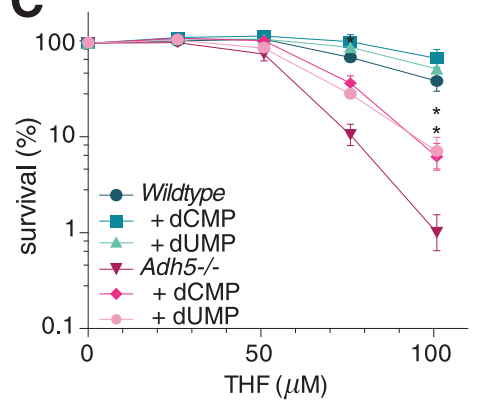

D

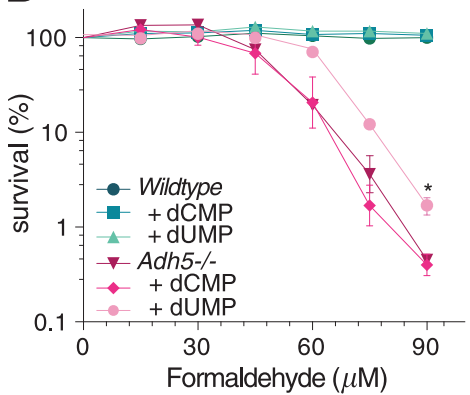

Fig. 3 DNA damage caused by THF is suppressed by addition of dUMP, dCMP, 5-fluorouracil, or the reducing agent 2mercaptoethanol. a Cartoon depicting the chemical reaction carried out by the TYMS enzyme. b Western blot analysis of $A d h 5^{-1-}$ DT40 whole-cell extracts upon exposure to increasing doses of THF for $16 \mathrm{~h}$. $A d h 5^{-1-}$ DT40 cells were grown for 3 days in media supplemented with $1 \mathrm{mM}$ of dUMP, IMP, or dCMP. The membrane was probed with anti-FANCD2, anti-ser345-CHK1, anti-ser139-H2AX, and anti-PCNA antibodies. c MTT assay of wild-type and $A d h 5^{-1-}$ DT40 cells grown in media supplemented with dCMP or dUMP for 3 days and then

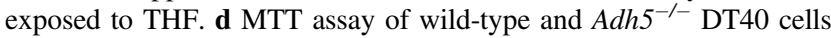

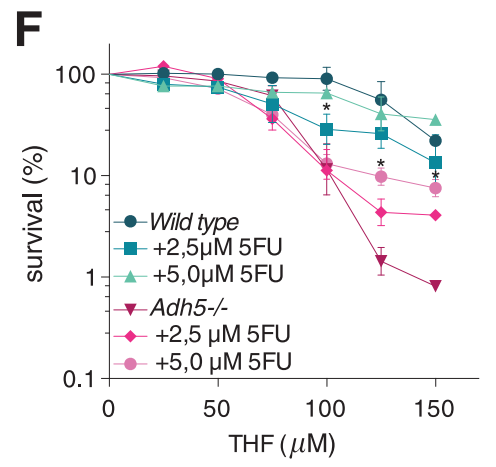

G

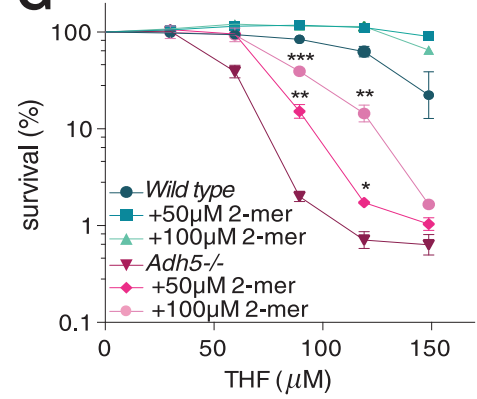

grown in media supplemented with dCMP or dUMP for 3 days exposed to formaldehyde. e Top, bar plot showing the quantitation of ser139-H2AX signal using the Fiji software. Bottom, western blot of $A d h 5^{-/-}$whole-cell extracts upon exposure to THF $(150 \mu \mathrm{M})$ and 5-fluorouracil $(\mathrm{FU}, 10 \mu \mathrm{M})$ for $6 \mathrm{~h}$. The membrane was probed with anti-ser139-H2AX and anti-PCNA (loading control) antibodies. Representative images of two independent experiments are shown. $\mathbf{f}, \mathbf{g}$

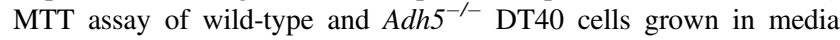
supplemented with 5 -FU (f 2.5 and $5.0 \mu \mathrm{M}$ ) or 2-mercaptoethanol (g 50 and $100 \mu \mathrm{M}$ ) and THF for 3 days. Data represent mean \pm s.d. of three independent experiments carried out in duplicates

\section{Results}

\section{Adh5- and Fanc-deficient chicken pre-B DT40 cells are hypersensitive to THF}

It has previously been demonstrated that formaldehyde readily reacts with THF to form 5,10-me-THF (Supplementary figure 1A), the active co-factor involved in $\mathrm{C} 1$ metabolism [32]. Firstly, we assessed the viability of $A d h 5^{-1-}$ DT40 cells upon formaldehyde exposure. As can be seen in Fig. 1a, the viability of these cells rapidly dropped.
Strikingly, the viability of $A d h 5^{-/-}$cells also decreased upon THF exposure compared to wild-type cells (Fig. 1b). We also determined the viability of DT40 $\mathrm{Fancc}^{-}, \mathrm{Fancf}^{-1}$ cell lines upon THF exposure showing similar results (Fig. 1c). Moreover, the observed sensitivity was specific to THF, as $A d h 5^{-1-}$ cells were not sensitive to other $1 \mathrm{C}$ folate derivatives such as folic acid, folinic acid, or the methionine cycle chemical S-adenosyl-methionine (SAM) (Fig. 1d, e, f). These data suggest that unlike other folate derivatives or SAM, THF is cytotoxic to cells lacking the FA DNA repair pathways or Adh5 at the tested concentrations. 

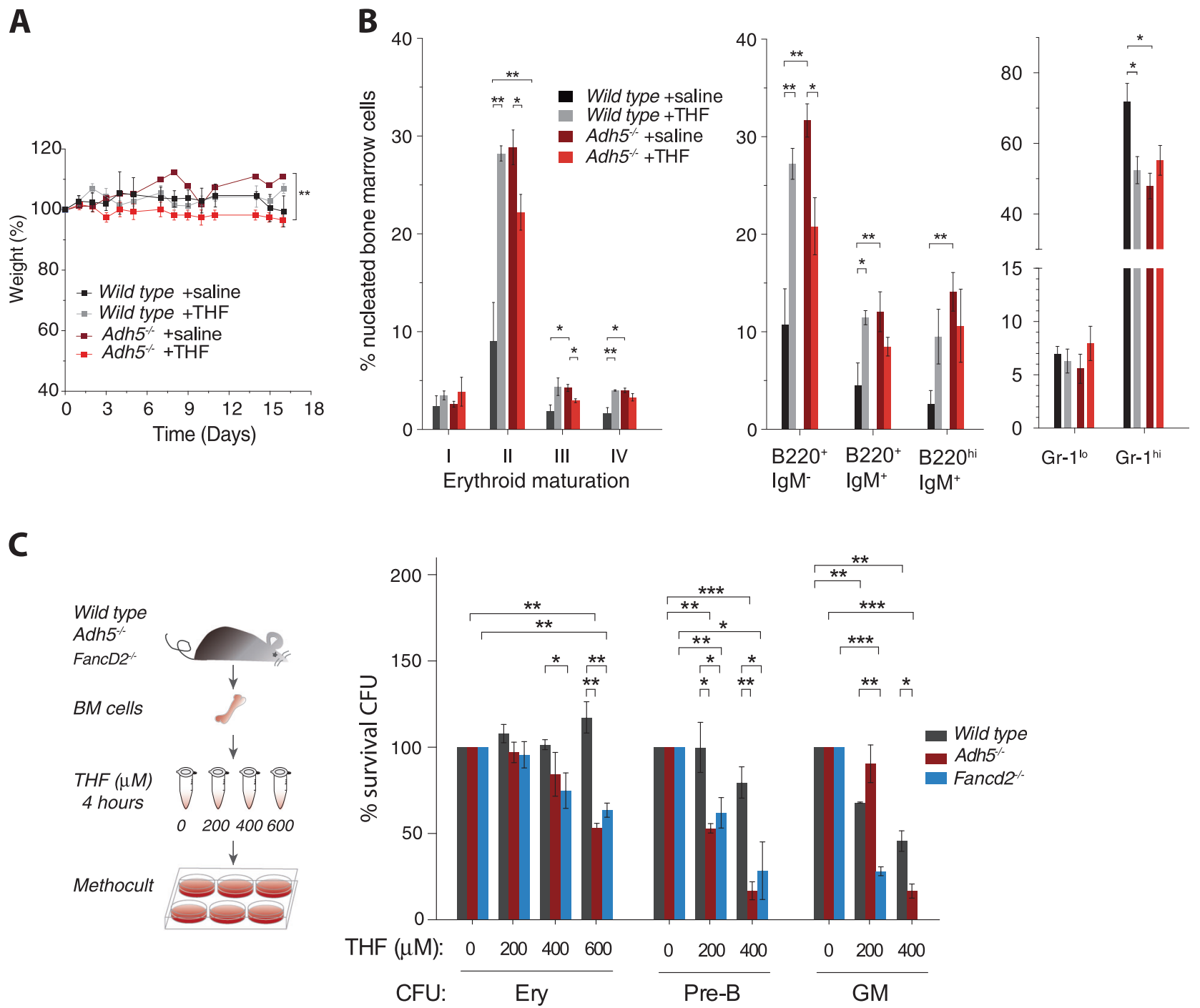

Fig. 4 THF exposure affects murine hematopoiesis. a Weight of Adh5 ${ }^{+/+}$(left) or $A d h 5^{-/-}$(right) mice exposed to THF. b Left, frequency of erythroid cells at each stage of differentiation in the bone marrow of mice exposed to THF. Middle, frequency of B-cell populations in the bone marrow of mice exposed to THF. Right, frequency of $\mathrm{Gr}^{+}{ }^{+} \mathrm{Mac} 1$ ${ }^{+}$and $\mathrm{Grl}^{+} \mathrm{Mac1}^{\mathrm{hi}}$ cell populations in the bone marrow of mice exposed to THF $(n=4, * P<0.05, * * P<0.01, * * * P<0.001)$. c Left, Scheme depicting the ex vivo THF treatment of BM cells and growth

\section{THF causes genomic instability and activation of the DNA damage response in Adh5- and FA-deficient cells}

Next, we addressed whether THF activated the DDR. Wildtype and $A d h 5^{-/-}$DT40-deficient cells were exposed to THF and subjected to immunofluorescence to assess the formation of FANCD2 and phosphorylated serine139 $\mathrm{H} 2 \mathrm{AX}$ (ser139-H2AX) foci. Unlike in wild-type cells, THF strongly promoted FANCD2 and ser139-H2AX focus formation in $A d h 5^{-/-}$cells (Fig. 2a). Thus, THF exposure promoted FANCD2 monoubiquitination in $A d h 5^{-/-}$but not in semisolid media. Right, bar plot depicting the relative survival of CFU lineage-committed progenitor cells seeded on methocult media (CFU-Ery, CFU-pre-B, and CFU-GM) of bone marrow cells obtained from mice. Wild-type, Adh5 ${ }^{-/-}$, and Fancd $2^{-/-}$bone marrow cells from three mice were enumerated, exposed ex vivo to 200,400 , and $600 \mu \mathrm{M}$ THF for $4 \mathrm{~h}$, and seeded in duplicate in 24 -well plates. Data represents mean \pm s.e.m. of two independent experiments

in wild-type cells in a dose-dependent manner (Fig. 2b). Fancf $^{-1}$ cells also showed increased ser139-H2AX phosphorylation upon THF exposure, suggesting the FA pathway was critical to prevent DDR activation upon THF exposure (Fig. 2b). We also tested if THF-adducted DNA elicited an ATR-dependent DDR by assessing the phosphorylation at serine 345 of the ATR substrate CHK1. As can be seen in Fig. 2b, CHK1 was readily phosphorylated at ser345 upon THF exposure, suggesting that THF-induced DNA damage blocked the progression of the replication fork. Also, the addition of the CHK1 inhibitor UCN-01 exacerbated the THF-dependent ser139-H2AX 
phosphorylation in $A d h 5^{-/-}$cells, suggesting that CHK1 is required for the maintenance of the replication fork stability upon THF DNA damage. Consistent with previously published results, inhibition of the Non-Homologous End joining (NHEJ) kinase DNA-pKcs decreased ser139-H2AX signal (Fig. 2c), suggesting that aberrant repair of THFmediated DNA damage engaged NHEJ machinery resulting in cell death [41, 42].

Next, we aimed to determine whether THF exposure promoted genome instability by quantification of the frequency of chromosome and chromatid breaks in metaphase spreads. Adh $5^{-/-}$cells exposed to THF accumulated more chromatid breaks and radials formation than wild-type cells (Fig. 2d), suggesting that THF provoked DNA damage during $\mathrm{S}$ or $\mathrm{G} 2$ cell cycle phases. Next, we studied whether THF was able to induce DNA damage by looking at the induction of sister chromatid exchanges (SCEs), an outcome of cross-over formation during Homologous recombination (HR). Under unperturbed conditions, wild-type DT40 cells presented an average of $\sim 1.72$ SCEs per metaphase, whereas $\mathrm{Fancf}^{-1-}$ cells showed $\sim 4.12$ SCEs per metaphase. Adh5 ablation did not increase SCEs (Adh5 $5^{-/-}$ $\sim 1.8$ SCEs) suggesting that accumulation of endogenous formaldehyde caused by loss of the Adh5 gene did not affect steady state SCEs (Fig. 2e). The frequency of SCEs in the wild-type strain remained unchanged upon THF treatment, but it strikingly increased in $A d h 5^{-/-}$cells upon THF exposure ( 3.49 SCEs per metaphase) (Fig. 2e). Finally, Fancf $^{-1-}$ cells showed no further increase in SCEs frequency upon THF exposure ( $\sim 4.12$ vs. $\sim 4,30$ SCEs per metaphase), suggesting that Fanconi-deficient cells do not elicit a HR-dependent repair activity upon THF exposure (Fig. 2e). Overall, these data suggest that THF is able to cause DNA damage, replication fork blockage, and activation of the DDR. Therefore, THF promotes chromosome breaks and genome instability in Adh5-deficient cells, necessitating the Fanconi anemia pathway to maintain genome integrity.

\section{THF-mediated DNA damage is due to alteration in the pool of nucleotide monophosphate substrates of the TYMS enzyme}

5,10-me-THF is the active co-factor of the TYMS enzyme involved in the conversion of dUMP into dTMP for DNA synthesis (Fig. 3a) and it is released as dihydrofolate. We reasoned that THF-mediated DNA damage could be due to elevated amounts of the co-factor 5,10-me-THF generated from the spontaneous covalent attachment of endogenously generated free formaldehyde to THF impacting on the overall activity of the enzyme TYMS, thus imbalancing dUMP vs. dTMP. Supplementation of cell growth media with the TYMS substrate dUMP or dCMP efficiently decreased THF-mediated FANCD2 monoubiquitination, and phosphorylation of ser345-CHK1 and ser139-H2AX (Fig. 3b), whereas, IMP supplementation did not suppress the THF-mediated DNA damage. Strikingly, dUMP supplementation partially suppressed THF and formaldehyde-

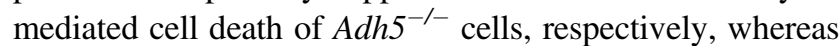
dCMP partially suppressed only THF-mediated cell death (Fig. 3c, d). We corroborated our results by exposing Adh $5^{-/-}$-deficient cells to the TYMS inhibitor 5-Fluorouracil (5-FU). As seen in Fig. 3e, addition of 5-FU partially suppressed the THF-mediated ser139-H2AX phosphorylation and improved cell survival (Fig. 3f). We also corroborated that 2-mercaptoethanol partially suppressed the THF-mediated cytotoxicity (Fig. 3g), in agreement with previously published results [41]. Taken together, these data suggest that THF-dependent DDR activation and cell death in $A d h 5^{-/-}$cells are due to depletion of the dUMP and dCMP pools, substrates of the TYMS enzyme. Overall, these data suggest that THF-mediated DNA damage is due to increased activity of the TYMS that ultimately impact on the dNMP levels, which inflicts DNA damage and chromosome instability.

\section{THF increases genomic instability and affects survival of hematopoietic-committed cells in vivo}

To determine whether some of the phenotypes seen in Adh5 ${ }^{-I}$ FancD $^{-I-}$ double-knockout mice could be related to THF metabolism, we exposed congenic $A d h 5^{-/-}$mice to THF. Unlike wild-type mice, upon THF exposure, $A d h 5^{-/-}$ animals stopped gaining weight (Fig. 4a). We determined the blood counts of these animals, not showing any remarkable changes (Supplementary figure 2). Next, we investigated whether THF exposure affected the differentiation process of lineage-committed cells by flow cytometry. Exposure of wild-type animals to THF markedly increased the frequency of erythroblasts at stage II and of B-cell precursors $\operatorname{IgM}^{-}$and $\operatorname{IgM}^{+}$, and decreased the frequency of $\mathrm{gr}^{\mathrm{hi}}$ cells suggesting that excess of THF affected hematopoietic differentiation (Fig. $4 \mathrm{~b}$ and supplementary figure 3). In clear contrast, the increase in the frequency of erythroblasts at stage II, III, and IV, $\mathrm{IgM}^{-}$and $\mathrm{IgM}^{+}$precursor B-cell populations were all alleviated by THF, whereas granulocytic precursors remained unaffected. We determined the functional ability of early lineage-committed precursor cells (CFU-ery, pre-B, and GM) to form colonies in methylcellulose media upon ex vivo THF treatment (Fig. 4c). Lack of of Adh5 or Fancd 2 rendered CFU-ery precursor cells sensitive to THF, and exacerbated the sensitivity of pre-B and GM CFUs to THF (Fig. 4c) compared to control animals, suggesting that THF differentially affected the survival of CFU-preB and CFU-GM progenitor cells, and that Adh5 

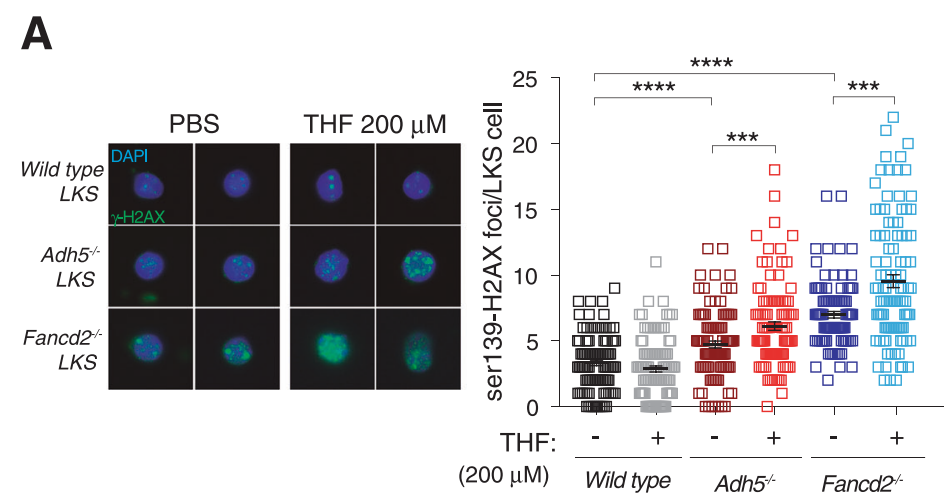

B
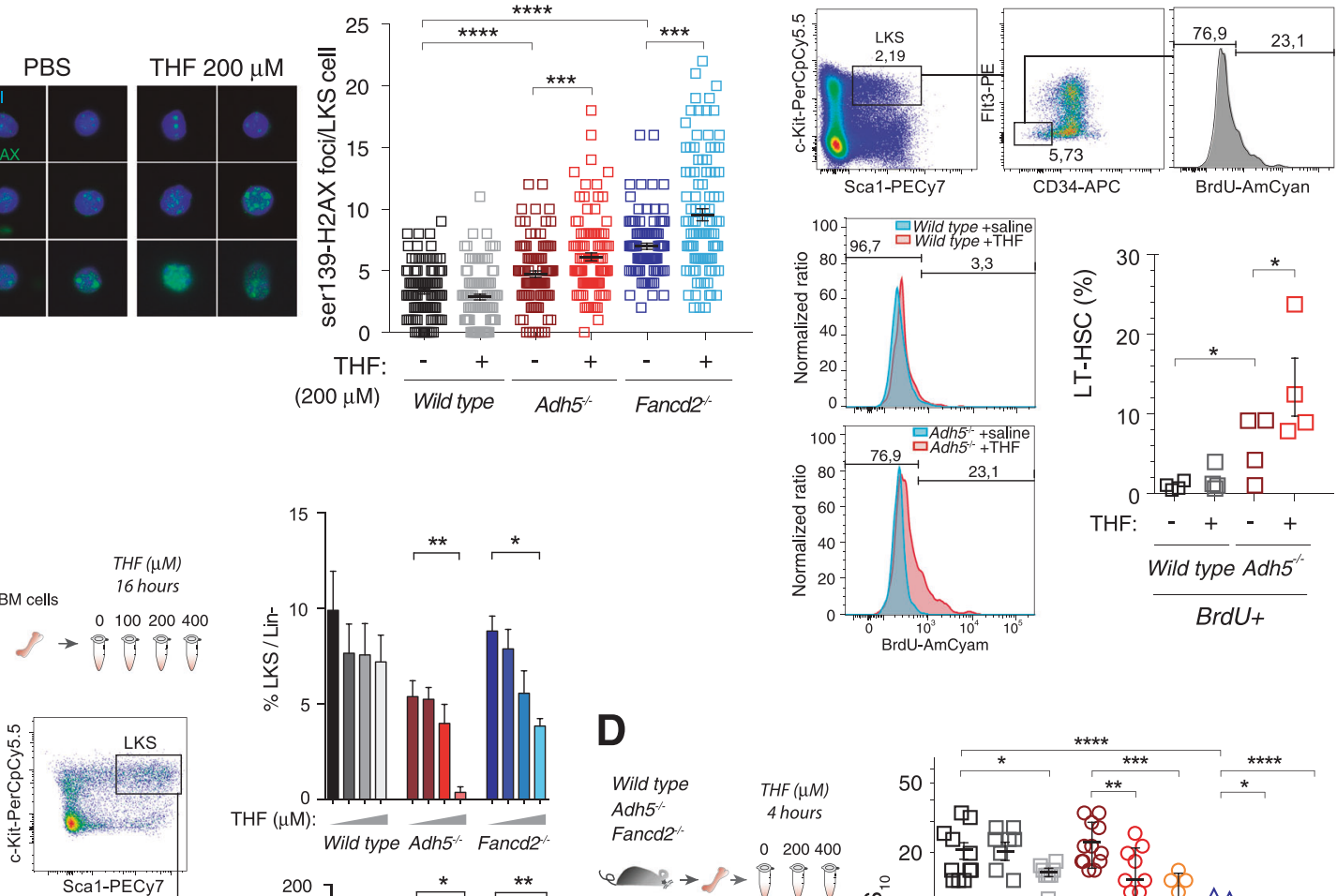

D
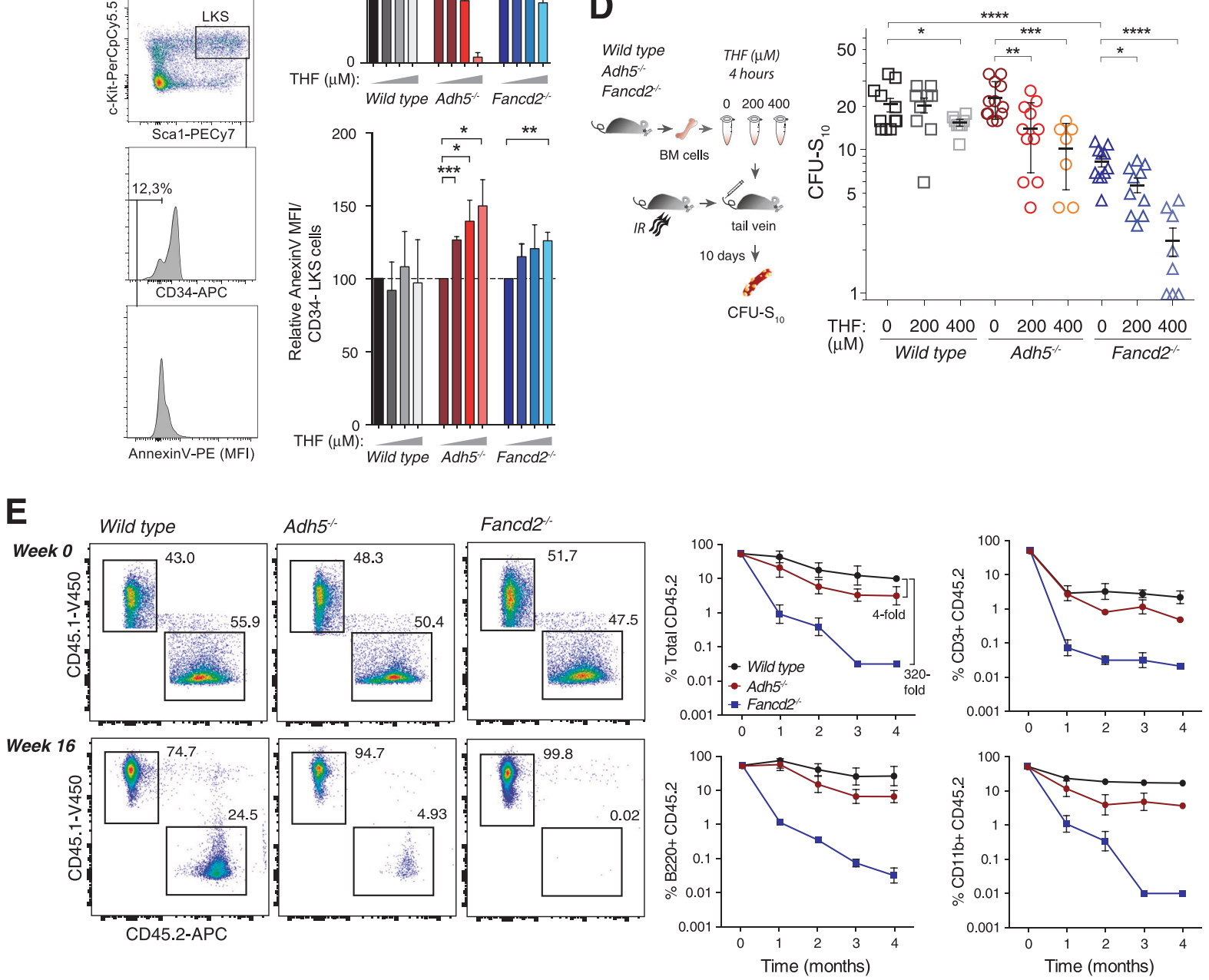

and Fancd 2 protect lineage-committed cells from THF toxicity.

Despite the effects of THF exposure on the survival of bone marrow progenitor cell, we did not observe any dramatic changes in bone marrow cellularity (Supplementary figure 4D). We determined whether THF exposure impacted on the development of immune organs such as spleen and thymus. Spleens from control and $A d h 5^{-l-}$ mice 
Fig. 5 THF exposure is genotoxic to HSPCs. a Left, representative immunofluorescence images of FACS-sorted LKS bone marrow cells from $A d h 5^{-1-}, F a n c D 2^{-l-}$, and control mice exposed ex vivo to THF. b Right, plot showing the number of ser139-H2AX foci per LKS cell upon THF treatment. b Top, gating strategy to measure $\mathrm{BrdU}^{+} \mathrm{LT}$ HSCs. Bottom left, overlay FACS plot images of THF and mocktreated CD $34^{-} \mathrm{Flt}^{-}$LKS bone marrow cells from $\mathrm{Adh} 5^{+/+}$and Adh5 ${ }^{-I-}$ upon THF exposure. Bottom right, plot showing the frequency of $\mathrm{BrdU}^{+}$long-term (LT) HSCs from wild-type and $A d h 5^{-1-}$ mice $(n=$ 4) exposed to THF for 1 week. Data represents mean \pm s.e.m. c Left, scheme depicting the experimental approach to quantitate the relative mean fluorescence intensity (MFI) of AnnexinV in CD34- LKS bone marrow cells upon THF exposure. Top right, frequency of LKS bone marrow cells upon THF exposure. Bottom right, (MFI) of AnnexinV in CD34- LKS bone marrow cells upon THF exposure. $\mathbf{d}$ Left, scheme depicting the colony formation unit spleen day-10 $\left(\mathrm{CFU}-\mathrm{S}_{10}\right)$ assay of bone marrow cells from $A d h 5^{-I-}, F a n c D 2^{-l-}$, and control mice. BM cells from two independent donors per genotype were enumerated, exposed ex vivo to 200 and $400 \mu \mathrm{M}$ THF for $4 \mathrm{~h}$, and tail-vein injected into lethally irradiated mice. Right, plot showing the number of CFU$\mathrm{S}_{10}$ colonies obtained from spleens of recipient mice injected with THF-treated $A d h 5^{-1-}, F a n c D 2^{-l-}$, and control BM cells. e Left, representative FACS plot showing the competitive repopulation assay. A total of $1 \times 10^{5}$ C57BL/6-Ly5.1 bone marrow cells and $1 \times 10^{5}$ wildtype, $A d h 5^{-1-}$, or Fancd2 $2^{-I-}$ C57BL/6-Ly5.2 bone marrow cells were mixed, exposed to THF $(200 \mu \mathrm{M}$ for $16 \mathrm{~h})$ and tail-vein injected into lethally irradiated C57BL/6-Ly5.1 mice $(n=3)$. Right, blood samples were taken every 4 weeks and the contribution of the mutant bone marrow cells to blood production was analyzed by flow cytometry using CD45.1, CD45.2, B220, CD3, and CD11b antibodies

exposed to THF in vivo were similar in weight (Supplementary figure 4A). Flow cytometry analyses of splenic cell populations showed an increased $\mathrm{CD} 4^{+}$in $A d h 5^{-l-}$ spleens, whereas spleens from wild type presented a relative increase of $\mathrm{CD}^{+}$and $\mathrm{CD}^{+}$(Supplementary figure $4 \mathrm{~A}$ ) conversely to peripheral blood B- and T-cell populations, whereas these changes did not occur in $A d h 5^{-/-}$mice (Supplementary figure 4C). $A d h 5^{-1-}$ thymi were smaller than control thymi, probably due to the additional role of Adh5 in T-cell development previously reported [39] (Supplementary figure $4 \mathrm{~B}) . \mathrm{CD}^{+}$population increased upon THF exposure in wild-type but not in $A d h 5^{-1-}$ mice. Overall, these data suggest that THF affected the survival of all the blood lineage precursor cells tested (B, erythroid, and granulocyte-macrophage precursor cells).

\section{Adh5 and the Fanconi anemia pathway are required to maintain the functionality of HSPCs upon THF exposure}

We next addressed whether THF might also be detrimental for HSPC homeostasis by looking for signs of DNA damage in the bone marrow compartment. The frequency of micronucleated polychromic (MN-PCEs) and normochromic (MN-NCEs) erythrocytes in wild-type and $A d h 5^{-/-}$ animals was determined (Supplementary figure 5A)

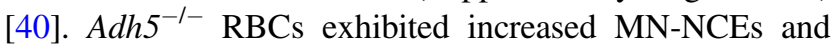

decreased MN-PCEs, suggesting that the $A D H 5$ gene is required to maintain genome integrity in bone marrow cells. Moreover, THF exposure increased the frequency of MNPCEs, suggesting that THF caused genome instability in Adh $5^{-1-}$ bone marrow cells.

We also determined whether sorted LK and LKS cell populations showed increased ser139-H2AX foci formation upon THF exposure. Both progenitor and stem wild-type cells barely showed any increase in ser139-H2AX foci formation upon THF exposure. In stark contrast, $A d h 5^{-1-}$ or Fancd $2^{-l-}$ LKS and LK cells showed increased ser139H2AX foci formation upon THF treatment (Fig. 5a and Supplementary figure 6), suggesting that HSPCs from Adh5- or Fancd2-deficient backgrounds exhibited DNA damage caused by exposure to THF. The presence of DNA damage might provoke HSCs to exit dormancy and enter the cell cycle. Therefore, we measured the frequency of cycling LT-HSC upon THF exposure. BrdU ${ }^{+}$LT-HSC was slightly increased in $A d h 5^{-1-}$ mice, suggesting adh5 was required to maintain HSC quiescence. Strikingly, THF exposure markedly increased the frequency of LT-HSC in $A d h 5^{-l-}$ compared to wild-type animals, suggesting that THF exposure affected HSC quiescence (Fig. 5b).

We also quantitated the frequency of LK and LKS cells by flow cytometry (supplementary figure 5A, B and C). THF in vivo exposure of $A d h 5^{-1-}$ mice decreased the frequency of LK cells ( $\sim 10 \%$ less), whereas the LKS cell population doubled (from $\sim 3$ to $\sim 7 \%$ of the Lin - bone marrow population) (supplementary figure $7 \mathrm{~A}$ ). Moreover, the frequency of long-term (LT) and short-term HSC increased, whereas Multipotent progenitors (MPP) consequently decreased upon THF treatment (supplementary figure 7B). Moreover, common myeloid precursors (CMPs) were unaffected, but granulocyte-macrophage progenitor contracted upon THF treatment (supplementary figure 7C), in agreement with the results obtained in the CFU-GM methylcellulose assay.

To further gain insights into whether THF affected the survival outcome of HSPCs, we set out two experimental approaches. First, we performed Annexin-V determination of the CD34- LKS population (LT-HSCs) by flow cytometry upon in vitro exposure to THF for $16 \mathrm{~h}$ (Fig. 5c), showing reduced frequency of LKS population of THFtreated Adh $5^{-1-}$ and Fancd $2^{-1-}$ compared to wild-type bone marrow cells, accompanied by an increased frequency of AnnexinV-positive CD34-LKS cells (Fig. 5c), suggesting that THF in vitro treatment affected HSCs cell survival by inducing apoptosis. Secondly, under the same experimental conditions, we determined the frequency of DAPI-positive LT-HSC obtaining similar results (supplementary figure 7D).

We next addressed the ability of HSCs to form colonies in the in vivo colony-forming unit spleen assay $\left(\mathrm{CFU}-\mathrm{S}_{10}\right)$ 
upon THF exposure. Exposure of $A d h 5^{-1-}$ or Fancd2 $2^{-l-}$ bone marrow cells to THF for $4 \mathrm{~h}$ (Fig. 5d, left) dramatically reduced the frequency of CFU- $\mathrm{S}_{10}$ colonies obtained compared to controls (Fig. 5d, right). Finally, we assessed the frequency of HSCs upon THF exposure by competitive repopulation assay. We transplanted equal number of wildtype (CD45.1) and mutant (Adh5 ${ }^{-1-}$ or Fancd2 $2^{-1-}$ CD45.2) bone marrow cells and determined the contribution of the mutant HSCs to peripheral blood production. We found that Adh5- and Fancd2-mutant HSCs had a fourfold and 320fold reduction, respectively, in their ability to contribute to blood production. Taken together, these data suggest that Adh 5 and Fancd 2 protect HSCs from toxic consequences of THF exposure, and the presence of DNA damage caused by THF accounted for the loss of HSCs viability.

\section{Discussion}

Our data uncover a quite detrimental consequence of excess of THF, which might be related to blood disorders and increased risk of cancer. THF exposure decreases the survival of blood cells with limited capacity of formaldehyde clearance or DNA repair. The genetic dissection shows that several DNA repair pathways are committed to fixing DNA lesions caused by THF. Due to the phosphorylation of the DNA damage checkpoint kinase CHK1, THF blocks the progression of the replication fork, eventually leading to exacerbated ser139 H2AX phosphorylation and DSB formation as evidenced by the increased chromosome breaks upon THF exposure. Moreover, inhibition of the main DSB kinase DNA-pk decreased the ser139-H2AX signal upon THF exposure in $A d h 5^{-l-}$ cells, similar to Fanconi-deficient cells exposed to cisplatin or mitomycin C [41, 42]. These unprecedented observations suggest that the pool of free formaldehyde might disturb the timely progression of the replication fork through modification of THF, due to changes in the dCMP and dTMP pools, in addition to the release of formaldehyde from the spontaneous breakdown of the THF molecule [38]. A likely mechanism would involve the depletion or imbalance of the nucleotide pool required for replication and repair due to overactive TYMS. Therefore, an unanticipated biological function of Adh5 could be the active removal of formaldehyde to avoid TYMS over activity and unscheduled DNA synthesis. dNMP imbalance or depletion has previously been shown to affect the timely replication of DNA, eventually leading to replication fork collapse under certain circumstances. The protection of the replication fork caused by dNTPs pool depletion upon HU exposure is controlled by the ATR kinase [43]. ATR defects in humans and humanized mouse models of Seckle syndrome cause microcephaly, dwarfism, and defective DDR [44, 45]. Strikingly, the overexpression of the regulatory subunit of the ribonucleotide reductase RRM2 alleviated the activation of the DDR in humanized ATR mouse models, suggesting that insufficient dNMP supplies accounts, at least in part, for the genomic instability seen in these mice [46]. In agreement with this idea, many FA-deficient human cells are also sensitive to the ribonucleotide reductase inhibitor hydroxyurea [47]. Overall, these data suggest that the FA pathway plays a widespread role in the protection of replication forks upon nucleotide depletion. An alternative and provocative explanation for the suppression of the DDR seen by dUMP supplementation could be due to the reactive nature of dUMP against THF or formaldehyde, however this hypothesis requires further investigation. The use of uracil or cytidine derivatives could be tested for their ability to decrease genomic instability. This approach might represent a potential therapeutic option for FA patients with a clear benefit for human health.

BMF in FA patients is believed to occur as a consequence of compromised HSC function due to intrinsic and extrinsic factors, which render HSCs incapable of dealing with perturbed hematopoietic demands under hematopoietic stress $[27,28]$. Compelling genetic evidence clearly suggest that aldehyde-driven toxicity is perhaps the main mechanism involved in the attrition of the HSC pool, developmental abnormalities, and the high predisposition to cancer seen in FA $[19,48]$. Our data suggest that the well-tolerated folate derivative THF might be a source of genomic instability in the absence of DNA repair mechanisms. The increased incidence of neoplasia observed upon folate intake in mouse models of colorectal and prostate cancer supports this idea, therefore challenging the proposed safety of this vitamin [49-52]. In mice, HSCs are primarily maintained in a quiescent $\mathrm{G}_{0}$ state, the burden of reactive aldehydes, and ROS are kept low and the DDR seems to be attenuated, in stark contrast to cycling fetal HSCs where the majority of these genes are highly transcribed to limit the mutagenicity caused by endogenous chemicals [53-54]. Our results shows that HSPCs from Adh5- or FancD2deficient mice presented increased number of ser139-H2AX foci, decreased repopulating capacity in the CFU-spleen assay upon THF exposure, and loss of HSCs by apoptosis, suggesting that THF was highly toxic to these cells. Moreover, Adh5-deficient myeloid and erythroid lineagecommitted precursors were more sensitive to THF, and the frequency of cycling HSCs in the absence of Adh5 was increased upon THF exposure. These data fit with a model in which THF exposure causes widespread DNA damage, which affects every blood compartment. Likewise, THF acting through direct attachment to formaldehyde, might speed the hematopoietic process, therefore causing a transient depletion of several progenitor cells (e.g., B220 ${ }^{+} \mathrm{IgM}^{-}$ lymphoid, stage II erythroid progenitors). This transient depletion would make intrinsically sick HSCs (due to 
Fancd2 or Adh5 deficiency) undergo apoptosis due to the reactivation of the metabolic burst upon cell cycle entry, resulting in devastating consequences. However, whether the increased DNA damage associated with THF exposure is due to direct DNA damage caused by THF or due to increased turnover of the blood progenitor cells that pull from HSCs down, needs further research. Due to the striking phenotype seen in FancD2 mice lacking Adh5, it is plausible that excess THF, formaldehyde, and lack of DNA repair drives BMF in this mouse model. This work has potentially relevant clinical implications, which could benefit patient care. Indeed, folate supplementation or fortification should be closely monitored in FA patients to establish correlations between BMF or AML onset and folate status.

Acknowledgements We thank Dr. K.J. Patel for providing the C57/ BL6 Adh5 $5^{-1-}$ - and Fancd $2^{-1-}$-deficient mice and key DT40-deficient cell lines. We also thank J. Surrallés for the generous gift of key reagents and cell lines.

Funding This work was supported by grants from the Spanish Ministry of Economy and Competitiveness MINECO [BFU2013-42918P], Instituto de Salud Carlos III [CP12/03273, AES15/01409], and the European Union (FEDER) to I.V.R. C.B.G.-C. was funded by BFU2013-42918-P, and I.T.G. was funded by CP12/03273. I.V.R. was a recipient of a Ramón y Cajal contract [RYC-2015-18670].

\section{Compliance with ethical standards}

Conflict of interest The authors declare that they have no conflict of interest.

\section{References}

1. Hanahan D, Weinberg RA. Hallmarks of cancer: the next generation. Cell. 2011;144:646-74.

2. Aguilera A, Garcia-Muse T. Causes of genome instability. Annu Rev Genet. 2013;47:1-32.

3. Pontel LB, Rosado IV, Burgos-Barragan G, Garaycoechea JI, Yu $\mathrm{R}$, Arends MJ, et al. Endogenous formaldehyde is a hematopoietic stem cell genotoxin and metabolic carcinogen. Mol Cell. 2015;60:177-88.

4. Garaycoechea JI, Crossan GP, Langevin F, Daly M, Arends MJ, Patel KJ. Genotoxic consequences of endogenous aldehydes on mouse haematopoietic stem cell function. Nature. 2012;489:571-5.

5. Crossan GP, Patel KJ. The Fanconi anaemia pathway orchestrates incisions at sites of crosslinked DNA. J Pathol. 2012;226:326-37.

6. Rosado IV, Langevin F, Crossan GP, Takata M, Patel KJ. Formaldehyde catabolism is essential in cells deficient for the Fanconi anemia DNA-repair pathway. Nat Struct Mol Biol. 2011;18:1432-4.

7. Langevin F, Crossan GP, Rosado IV, Arends MJ, Patel KJ. Fancd 2 counteracts the toxic effects of naturally produced aldehydes in mice. Nature. 2011;475:53-8.

8. Ceccaldi R, Sarangi P, D'Andrea AD. The Fanconi anaemia pathway: new players and new functions. Nat Rev Mol Cell Biol. 2016;17:337-49.
9. Zhang J, Dewar JM, Budzowska M, Motnenko A, Cohn MA, Walter JC. DNA interstrand cross-link repair requires replicationfork convergence. Nat Struct Mol Biol. 2015;22:242-7.

10. Duxin JP, Walter JC. What is the DNA repair defect underlying Fanconi anemia? Curr Opin Cell Biol. 2015;37:49-60.

11. Budzowska M, Graham TG, Sobeck A, Waga S, Walter JC. Regulation of the Rev1-pol zeta complex during bypass of a DNA interstrand cross-link. EMBO J. 2015;34:1971-85.

12. Zhang J, Walter JC. Mechanism and regulation of incisions during DNA interstrand cross-link repair. DNA Repair. 2014;19:135-42.

13. Klein Douwel D, Boonen RA, Long DT, Szypowska AA, Raschle $\mathrm{M}$, Walter JC, et al. XPF-ERCC1 acts in unhooking DNA interstrand crosslinks in cooperation with FANCD2 and FANCP/ SLX4. Mol Cell. 2014;54:460-71.

14. Duxin JP, Dewar JM, Yardimci H, Walter JC. Repair of a DNAprotein crosslink by replication-coupled proteolysis. Cell. 2014;159:346-57.

15. Knipscheer P, Raschle M, Smogorzewska A, Enoiu M, Ho TV, Scharer OD, et al. The Fanconi anemia pathway promotes replication-dependent DNA interstrand cross-link repair. Science. 2009;326:1698-701.

16. Schlacher $\mathrm{K}, \mathrm{Wu} \mathrm{H}$, Jasin $\mathrm{M}$. A distinct replication fork protection pathway connects Fanconi anemia tumor suppressors to RAD51BRCA1/2. Cancer Cell. 2012;22:106-16.

17. Schlacher K, Christ N, Siaud N, Egashira A, Wu H, Jasin M. Double-strand break repair-independent role for BRCA2 in blocking stalled replication fork degradation by MRE11. Cell. 2011;145:529-42.

18. Auerbach AD. Diagnosis of Fanconi anemia by diepoxybutane analysis. Curr Protoc Human Genet. 2015;85:8. 7. 1-17.

19. Alter BP. Fanconi anemia and the development of leukemia. Best Pract Res Clin Haematol. 2014;27:214-21.

20. Smith AR, Wagner JE. Current clinical management of Fanconi anemia. Expert Rev Hematol. 2012;5:513-22.

21. Alter BP. Fanconi's anemia, transplantation, and cancer. Pediatr Transplant. 2005;9:81-6.

22. Dietz AC, Orchard PJ, Baker KS, Giller RH, Savage SA, Alter $\mathrm{BP}$, et al. Disease-specific hematopoietic cell transplantation: nonmyeloablative conditioning regimen for dyskeratosis congenita. Bone Marrow Transplant. 2011;46:98-104.

23. Parmar K, D'Andrea A, Niedernhofer LJ. Mouse models of Fanconi anemia. Mutat Res. 2009;668:133-40.

24. Naka K, Hirao A. Maintenance of genomic integrity in hematopoietic stem cells. Int J Hematol. 2011;93:434-9.

25. Zhang H, Kozono DE, O'Connor KW, Vidal-Cardenas S, Rousseau A, Hamilton A, et al. TGF-beta inhibition rescues hematopoietic stem cell defects and bone marrow failure in Fanconi anemia. Cell Stem Cell. 2016;18:668-81.

26. Hadjur S, Ung K, Wadsworth L, Dimmick J, Rajcan-Separovic E, Scott RW, et al. Defective hematopoiesis and hepatic steatosis in mice with combined deficiencies of the genes encoding Fancc and $\mathrm{Cu} / \mathrm{Zn}$ superoxide dismutase. Blood. 2001;98:1003-11.

27. Garaycoechea JI, Patel KJ. Why does the bone marrow fail in Fanconi anemia? Blood. 2014;123:26-34.

28. Walter D, Lier A, Geiselhart A, Thalheimer FB, Huntscha S, Sobotta MC, et al. Exit from dormancy provokes DNA-damageinduced attrition in haematopoietic stem cells. Nature. 2015;520:549-52

29. Fox JT, Stover PJ. Folate-mediated one-carbon metabolism. Vitam Horm. 2008;79:1-44.

30. Mentch SJ, Locasale JW. One-carbon metabolism and epigenetics: understanding the specificity. Ann N Y Acad Sci. 2016;1363:91-8

31. Duthie SJ, Narayanan S, Brand GM, Pirie L, Grant G. Impact of folate deficiency on DNA stability. J Nutr. 2002;132:2444S-9S. 
32. Kallen RG, Jencks WP. The mechanism of the condensation of formaldehyde with tetrahydrofolic acid. J Biol Chem. 1966;241:5851-63.

33. Beaudin AE, Stover PJ. Folate-mediated one-carbon metabolism and neural tube defects: balancing genome synthesis and gene expression. Birth Defects Res C Embryo Today. 2007;81:183-203.

34. Christensen B. [Folate deficiency, cancer and congenital abnormalities. Is there a connection?]. Tidsskr Nor Laegeforen. 1996;116:250-4.

35. Duthie SJ. Folic acid deficiency and cancer: mechanisms of DNA instability. Br Med Bull. 1999;55:578-92.

36. Colapinto CK, O'Connor DL, Tremblay MS. Folate status of the population in the Canadian Health Measures Survey. Can Med Assoc J. 2011;183:E100-6.

37. Varela-Rey M, Woodhoo A, Martinez-Chantar ML, Mato JM, Lu SC. Alcohol, DNA methylation, and cancer. Alcohol Res. 2013;35:25-35.

38. Burgos-Barragan G, Wit N, Meiser J, Dingler FA, Pietzke M, Mulderrig L, et al. Mammals divert endogenous genotoxic formaldehyde into one-carbon metabolism. Nature. 2017;548:549-54.

39. Yang Z, Wang ZE, Doulias PT, Wei W, Ischiropoulos H, Locksley RM, et al. Lymphocyte development requires Snitrosoglutathione reductase. J Immunol. 2010;185:6664-9.

40. Balmus G, Karp NA, Ng BL, Jackson SP, Adams DJ, McIntyre RE. A high-throughput in vivo micronucleus assay for genome instability screening in mice. Nat Protoc. 2015;10:205-15.

41. Pace P, Mosedale G, Hodskinson MR, Rosado IV, Sivasubramaniam M, Patel KJ. Ku70 corrupts DNA repair in the absence of the Fanconi anemia pathway. Science. 2010;329:219-23.

42. Adamo A, Collis SJ, Adelman CA, Silva N, Horejsi Z, Ward JD, et al. Preventing nonhomologous end joining suppresses DNA repair defects of Fanconi anemia. Mol Cell. 2010;39:25-35.

43. Yazinski SA, Zou L. Functions, regulation, and therapeutic implications of the ATR checkpoint pathway. Annu Rev Genet. 2016;50:155-73.
44. O’Driscoll M. Mouse models for ATR deficiency. DNA Repair. 2009;8:1333-7.

45. O'Driscoll M, Ruiz-Perez VL, Woods CG, Jeggo PA, Goodship JA. A splicing mutation affecting expression of ataxiatelangiectasia and Rad3-related protein (ATR) results in Seckel syndrome. Nat Genet. 2003;33:497-501.

46. Lopez-Contreras AJ, Specks J, Barlow JH, Ambrogio C, Desler C, Vikingsson $\mathrm{S}$, et al. Increased Rrm2 gene dosage reduces fragile site breakage and prolongs survival of ATR mutant mice. Genes Dev. 2015;29:690-5.

47. Nomura Y, Adachi N, Koyama H. Human Mus81 and FANCB independently contribute to repair of DNA damage during replication. Genes Cells. 2007;12:1111-22.

48. Auerbach AD. Fanconi anemia and its diagnosis. Mutat Res. 2009;668:4-10.

49. Cole BF, Baron JA, Sandler RS, Haile RW, Ahnen DJ, Bresalier RS, et al. Folic acid for the prevention of colorectal adenomas: a randomized clinical trial. JAMA. 2007;297:2351-9.

50. Chae YK, Yun JH. Folic acid and prevention of colorectal adenomas. JAMA. 2007;298:1397

51. Figueiredo JC, Mott LA, Giovannucci E, Wu K, Cole B, Grainge MJ, et al. Folic acid and prevention of colorectal adenomas: a combined analysis of randomized clinical trials. Int $\mathrm{J}$ Cancer. 2011;129:192-203.

52. Tio M, Andrici J, Cox MR, Eslick GD. Folate intake and the risk of prostate cancer: a systematic review and meta-analysis. Prostate Cancer Prostatic Dis. 2014;17:213-9.

53. Beerman I, Seita J, Inlay MA, Weissman IL, Rossi DJ. Quiescent hematopoietic stem cells accumulate DNA damage during aging that is repaired upon entry into cell cycle. Cell Stem Cell. 2014;15:37-50.

54. Manesia JK, Xu Z, Broekaert D, Boon R, van Vliet A, Eelen G, et al. Highly proliferative primitive fetal liver hematopoietic stem cells are fueled by oxidative metabolic pathways. Stem Cell Res. 2015;15:715-21. 